\title{
Fracture analysis of the circulating pump bolts
}

\author{
Jiang Chengjun ${ }^{1 \mathrm{a}^{*}}$, Wang Wei ${ }^{1 \mathrm{~b}}$, Zou Xiaohuiic ${ }^{2 \mathrm{c}}$, Wang Jifeng ${ }^{1 \mathrm{~d}}$ \\ ${ }^{1}$ Shanghai Institute of Special Equipment Inspection \& Technical Research, Putuo, Shanghai, China \\ ${ }^{2}$ Shanghai Space Propulsion Technology Research Institute, Minhang, Shanghai, China
}

\begin{abstract}
The microstructure, micrograph of the fracture sections and the alloy elements distribution of the fractured flange-connecting bolts of $3 \#$ circulating pump in a power plant were analyzed by the scanning electron microscopy, the optical microscopy and the electron probe microanalysis. The results showed that the failed bolts' material is not the design material, and failure of the bolts is due to the stress corrosion crack propagation of the bolts' austenitic material by chloride ions in seawater.
\end{abstract}

\section{Induction}

A sudden abnormal noise was happened in 3\# circulating pump of a power plant in 2018, and then the pump was stopped running and lifted to find the reason. During examination, 4 bolts connecting the motor cover and the discharge cylinder of the pump were found to be fractured. During the time of other 20 flange-connecting bolts dismantled, 12 bolts were fallen off, and also other 4 bolts were fractured. In the past when routine inspection was taken in service, fracture of the flange-connecting bolts had been occurred sometimes, but the number of the fracture bolts did not exceed two tenth of the total in-service bolts. These bolts connecting the motor cover and the discharge cylinder is the important component to ensure normal operation of all circulating pumps. Because the design documentation of the bolts have been lost, replacement of the bolts is troublesome, and so it is essential and important to pinpoint the cause of these bolts failure.

\section{Fracture bolts, spare bolts and samples}

Eight samples (1\# 8\#) were selected for analysis by batch, as shown in Fig.1. 1\# sample is one of the fracture bolts, 2\# sample is a bolt used but without fractured, 3\# sample is a bolt used but without fractured too, 4\# sample is a spare bolt (non-used and not fractured), 5\#, 6\#, 7\# samples are nuts used, and 8\#sample is a spare nut.

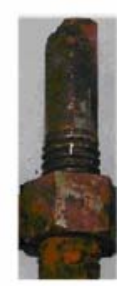

1\# sample

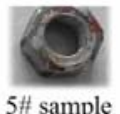

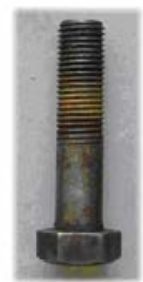

2\# sample

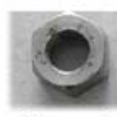

6\# sample

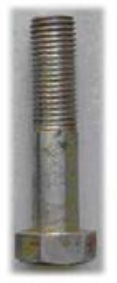

3\# sample

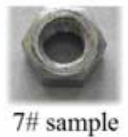

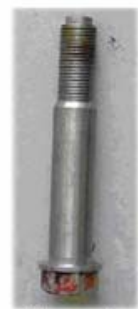

4\# sample

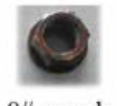

8 \# sample
Fig.1 Macrographs of $1 \#$ to $8 \#$ samples

\section{Chemical composition analysis of the samples}

According to the equipment manager, the flange-connecting bolts' material is austenitic stainless steel, but the concrete material brand is unclear. In order to confirm the actual bolts' material used in the circulating pump, the chemical compositions of these samples are analyzed, as shown in Tab.1.

\begin{tabular}{|c|c|c|c|c|c|c|c|c|}
\multicolumn{8}{c|}{ Tab.1 Chemical composition analysis of the samples } \\
Sample & $\begin{array}{c}1 \# \\
\text { sample }\end{array}$ & $\begin{array}{c}2 \# \\
\text { sample }\end{array}$ & $\begin{array}{c}3 \# \\
\text { sampl } \\
\mathrm{e}\end{array}$ & $\begin{array}{c}4 \# \\
\text { sample }\end{array}$ & $\begin{array}{c}5 \# \\
\text { sample }\end{array}$ & $\begin{array}{c}6 \# \\
\text { sample }\end{array}$ & $\begin{array}{c}7 \# \\
\text { sample }\end{array}$ & $\begin{array}{c}8 \# \\
\text { sample }\end{array}$ \\
\hline $\mathrm{C}$ & 0.13 & 0.06 & 0.05 & 0.10 & 0.14 & 0.13 & 0.05 & 0.13 \\
\hline $\mathrm{Mn}$ & 14.5 & 0.48 & 0.52 & 6.90 & 0.27 & 0.40 & 1.66 & 0.31 \\
\hline $\mathrm{Si}$ & 0.22 & 0.62 & 0.30 & 0.47 & 0.32 & 0.65 & 0.62 & 0.32 \\
\hline
\end{tabular}

\footnotetext{
$\mathrm{a}^{*}$ Corresponding author's e-mail: jiangchengjun1984@163.com

bemail: 13921619995@163.com, cemail: yhjbetter@126.com, demail: wangjf@ssei.cn
} 


\begin{tabular}{|c|c|c|c|c|c|c|c|c|}
\hline $\mathrm{S}$ & 0.013 & 0.002 & 0.004 & 0.006 & 0.003 & 0.003 & 0.006 & 0.003 \\
\hline $\mathrm{P}$ & 0.025 & 0.031 & 0.017 & 0.031 & 0.014 & 0.012 & 0.030 & 0.016 \\
\hline $\mathrm{Cr}$ & 9.18 & 16.57 & 16.63 & 15.99 & 16.54 & 16.82 & 17.74 & 16.74 \\
\hline $\mathrm{Ni}$ & 0.21 & 4.85 & 4.89 & 7.31 & 2.34 & 2.43 & 8.91 & 2.31 \\
\hline $\mathrm{Mo}$ & 0.03 & 0.028 & 0.14 & 0.14 & 0.068 & 0.030 & 0.21 & 0.075 \\
\hline $\mathrm{Cu}$ & 0.42 & 2.88 & 3.45 & 0.31 & 0.08 & 0.08 & 0.13 & 0.092 \\
\hline $\mathrm{Ti}$ & $/$ & 0.020 & 0.010 & 0.014 & 0.010 & 0.006 & 0.57 & 0.022 \\
\hline $\mathrm{N}$ & $/$ & 0.05 & 0.06 & 0.10 & 0.068 & 0.031 & $/$ & 0.065 \\
\hline $\mathrm{Nb}$ & $/$ & 0.40 & 0.31 & 0.017 & 0.009 & 0.005 & $/$ & 0.010 \\
\hline $\mathrm{Al}$ & 0.004 & 0.020 & 0.03 & 0.009 & 0.032 & 0.008 & 0.077 & 0.032 \\
\hline
\end{tabular}

According to the analysis results shown in Tab.1, the material brands corresponding to similar elements in the world steel brands manual are listed in Tab. $2^{[1]}$.

Tab.2 The Corresponding material brands

\begin{tabular}{|c|l|}
\hline $\begin{array}{c}1 \# \\
\text { sample }\end{array}$ & $\begin{array}{l}\text { No specific material brand corresponding to } \\
\text { similar elements }\end{array}$ \\
\hline $\begin{array}{c}2 \# \\
\text { sample }\end{array}$ & $\begin{array}{l}\text { 0Cr17Ni4Cu4Nb ( belongs to martensite } \\
\text { precipitation-hardening stainless steel) }\end{array}$ \\
\hline $\begin{array}{c}3 \# \\
\text { sample }\end{array}$ & $\begin{array}{l}\text { 0Cr17Ni4Cu4Nb ( belongs to martensite } \\
\text { precipitation-hardening stainless steel) }\end{array}$ \\
\hline $\begin{array}{c}4 \# \\
\text { sample }\end{array}$ & $\begin{array}{l}1 \mathrm{Cr} 17 \mathrm{Mn} 6 \mathrm{Ni} 5 \mathrm{~N} \text { ( belongs to austenitic } \\
\text { stainless steel, but the nickel content is low) }\end{array}$ \\
\hline $\begin{array}{c}5 \# \\
\text { sample }\end{array}$ & $\begin{array}{l}1 \mathrm{Cr} 17 \mathrm{Ni2} \text { (belongs to martensitic stainless } \\
\text { steel) }\end{array}$ \\
\hline $\begin{array}{c}6 \# \\
\text { sample }\end{array}$ & $\begin{array}{l}1 \mathrm{Cr} 17 \mathrm{Ni2} \text { (belongs to martensitic stainless } \\
\text { steel) }\end{array}$ \\
\hline $\begin{array}{c}7 \# \\
\text { sample }\end{array}$ & $\begin{array}{l}0 \mathrm{Cr} 18 \mathrm{Ni} 9 \mathrm{Ti} \text { (belongs to austenitic stainless } \\
\text { steel) }\end{array}$ \\
\hline $\begin{array}{c}8 \# \\
\text { sample }\end{array}$ & $\begin{array}{l}1 \mathrm{Cr} 17 \mathrm{Ni2} \text { (belongs to martensitic stainless } \\
\text { steel) }\end{array}$ \\
\hline
\end{tabular}

According to the analysis results in Tab.1, the main alloy components of $1 \#$ sample are $\mathrm{Mn}$ and $\mathrm{Cr}$, and the $\mathrm{Mn}$ content is up to $14.5 \%$, so the material belongs to high manganese steel. On the contrary, $\mathrm{Cr}$ content is only $9.18 \%$ far from the minimum content $12 \%$ of stainless steel. The specific material brand of $1 \#$ sample cannot be confirmed compared with the world steel brands manual. In addition, the materials of the other samples are fall into

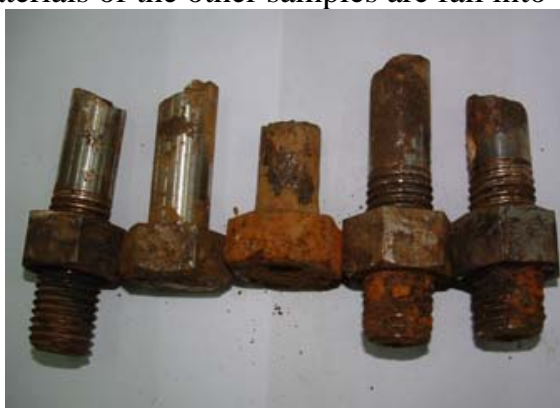

two categories: austenitic stainless steel and martensitic stainless steel[1]. The content of $\mathrm{Cr}$ and $\mathrm{Ni}$ in the fractured bolts is significantly lower than the unfractured bolt. It is certain that the fractured bolt is not stainless steel, because $\mathrm{Cr}$ and $\mathrm{Ni}$ are the main elements to improve the corrosion resistance in stainless steel. As a result, it is unreasonable to apply it in the corrosive environment of seawater. Since the original design documentation was lost, the plant should confirm with the supplier whether the bolts material is misused or not selected according to the purchase orders.

\section{Macromorphology of the bolts' fracture sections}

\subsection{Appearance analysis of the fractured bolts}

Some fractured bolts were collected for analysis, and the macrographs of these bolts are shown in Fig.2. It can be observed that the screw threads of these bolts are in good condition basically. After removing the rusts, no crack defect is observed in the screw threads. All these bolts fractured at the smooth part in the middle of the bolts. The bolts fractured part don't have the axial necking deformation by the appearance analysis, and also don't have the bending deformation. These characteristics indicate that the bolts fractured under low loads, which is generally considered as brittle fracture under low stress[2].

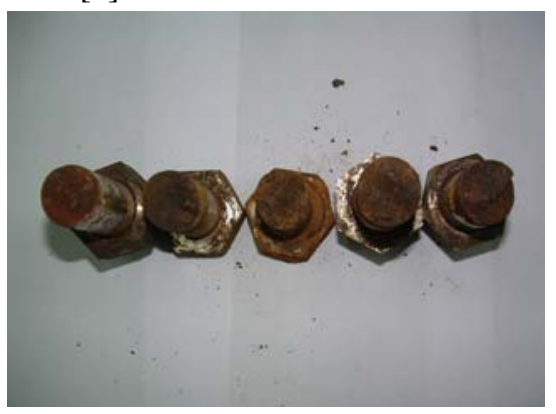

Fig.2 Axial macrograph (the left) and radial macrograph (the right) of some fractured bolts 


\subsection{Macromorphology analysis of the bolts fracture sections}

In order to observe the macromorphology characteristics of the bolt fracture sections clearly, two bolts were selected (the one in Fig.3 (a) is 1\# fractured sample, and that one in Fig.3 (b) is another chosen fractured bolt) for macromorphology analysis, and the photos of the bolts macromorphology were taken after removing dirt at the fracture sections, as shown in Fig.3.

It can be observed clearly that the left side of the fracture sections is the converging point of radiating stripes, which is the crack source. Observed the macroscopic characteristics of the entire fracture sections, there are some obvious radiating stripes of cracks growth on the fracture sections and this area is the cracks growth

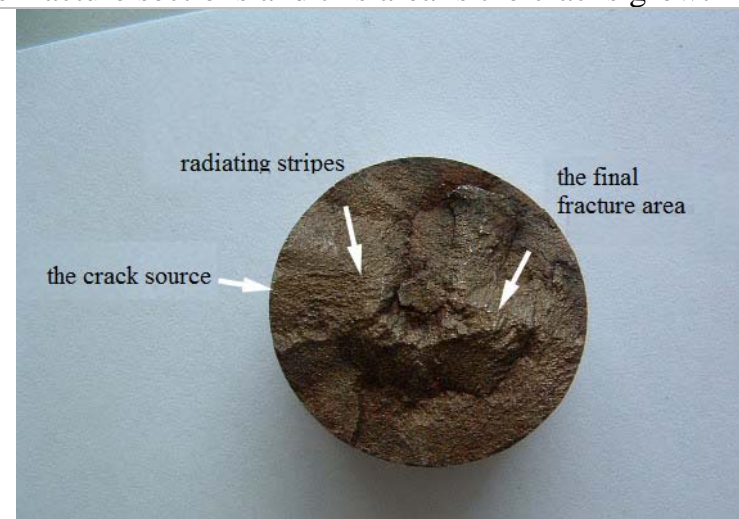

(a) area. The right part of the fracture sections shows obvious local tearing characteristics, which is the final fracture area[3]. The entire fracture sections are relatively flat, and no shear layer can be seen at the edge. In addition, there is no obvious defect at the fracture source, which is smooth. The color at the fracture source is dark black, and the final fracture area is lighter than the crack source. The fracture sections have obvious corrosion products, especially at the crack source.

In summary, the macromorphology of the fracture sections shows that the bolts fractured under low stress, which has the characteristics of stress corrosion. The bolts ruptured at the site where was washed away by the splash seawater, so the fracture reason should be related to the seawater corrosion.

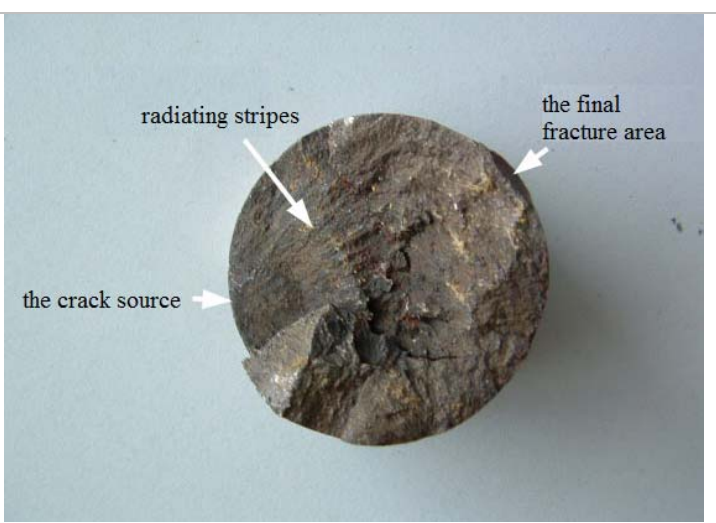

(b)

Fig.3 Macroscopical pictures of the bolts fracture sections

\section{Analysis of the metallographic structure and crack propagation path of the bolts}

\subsection{Microstructure analysis of the samples}

In order to analyze the metallographic structure of the

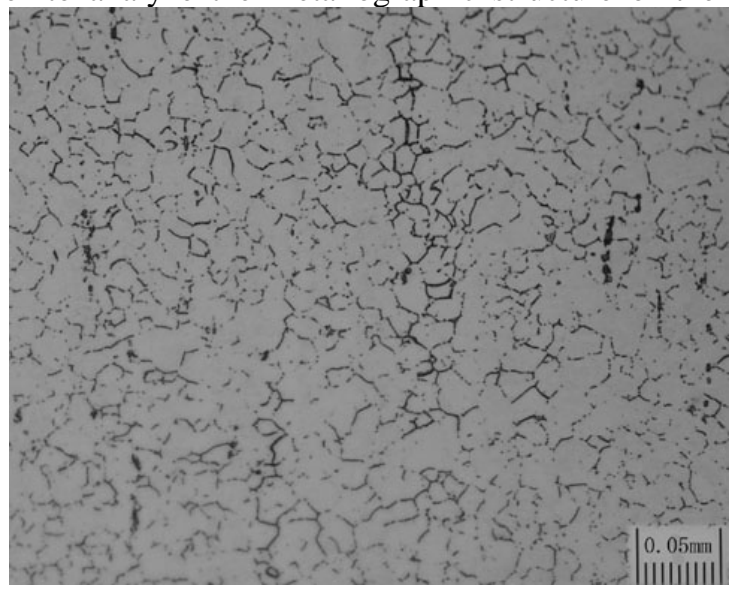

Fig.4 Metallographic structures of the middle zone

According to the metallographic structures of the sample in Fig.4, the structure is analyzed as austenite plus carbide[4]. The morphology is black carbides with the shape of small blocks and strips distributed on the bolts and distribution of the corrosion precipitations, the metallographic structure of $1 \#$ sample is analyzed. The metallographic structures are taken along the longitudinal direction of the sample, as shown in Fig.4.

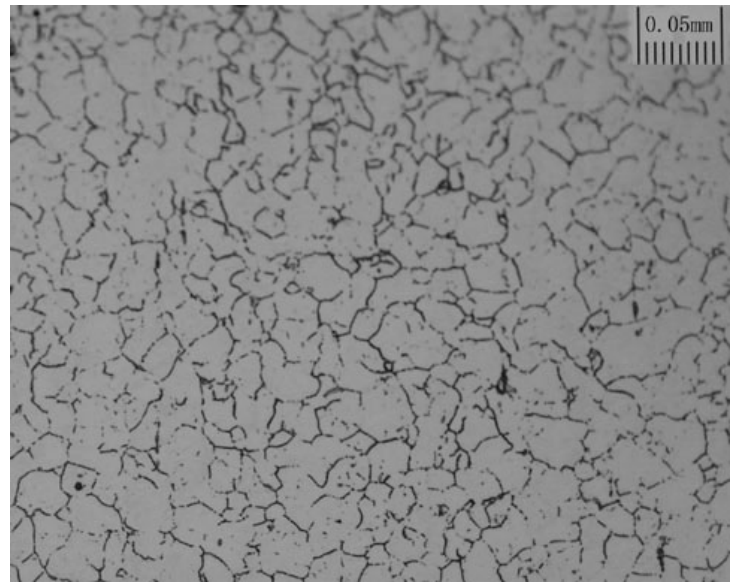

(left) and the marginal zone (right) of $1 \#$ sample austenite matrixes. The carbides in local regions are aggregated and a small amount of carbides exist in the matrixes. According to the characteristics of the carbides distribution, some carbides are judged in unmelted state at 
the grain boundary, which indicates that the heating temperature of the bolts in heat treatment process is too low to melt these carbides.

In general, carbides distributed along austenite grain boundary are mostly in the form of chromium carbide. These unmelted carbides aggregate at the grain boundary (called "poor chromium" phenomenon), which make the material become relatively weak parts in the grain boundary. In other words, the brittleness of the material increases greatly and the corrosion resistance of the material decreases greatly.

\subsection{Crack propagation path analysis of the bolts}

The crack growth near the fracture section of $1 \#$ sample is shown in Fig. 5 after the sample was cut off along the longitudinal section. The fracture section is often regarded as the main crack source, and concentration of the corrosion medium causes the crack initiation and propagation of secondary cracks. At the same time, the bolt rod edge (different from the lower edge of the fracture section) can be observed that has cracks initiation, and the crack propagation direction at the edge is from the bolt surface to inside, and most of the paths propagate along the grain boundary. This is due to distribution of a lot of strip carbides on the grain boundary of $1 \#$ sample, which significantly reduces the chromium content in this area and greatly increases the sensitivity factor of corrosion along the grain boundary [5].

It can be concluded that the main factor of the bolts fracture is the stress corrosion crack under low stress generated by the corrosion medium action in a certain environment for some time, and then the crack propagation was accelerated, and eventually the bolts fractured.

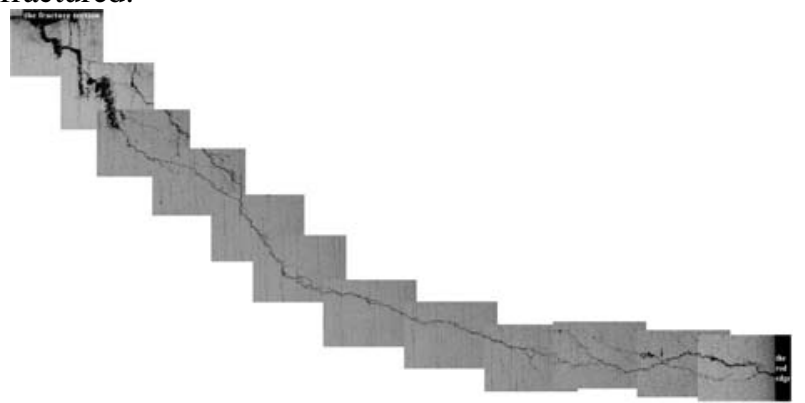

Fig.5 Crack growth pictures of the fracture along the longitudinal section of $1 \#$ sample

\section{Elemental energy spectrum analysis of the corrosion products}

In order to confirm the environmental media factors that lead to the stress corrosion of the bolts, energy spectrum analysis was carried out on the corrosion products of $1 \#$ sample fracture section. The analysis results are shown in Fig.6. In the corrosion products, the main nonmetal elements are chlorine and carbon, while the rest are oxygen and a little sulfur. The high content of zinc is due to the fact that the test section of energy spectrum analysis is located at the enriched part of zinc oxide generated by seawater corrosion. According to the elemental energy spectrum analysis, the corrosion products are mainly chloride, while the rest are oxides and carbides[6].Combined with the analysis of the environmental factors around the pump bolts, it can be confirmed that the medium factor leading to the stress corrosion of the bolts is mainly $\mathrm{Cl}$ ions in seawater, because austenite material is the most sensitive to the stress corrosion crack of $\mathrm{Cl}$ ions.

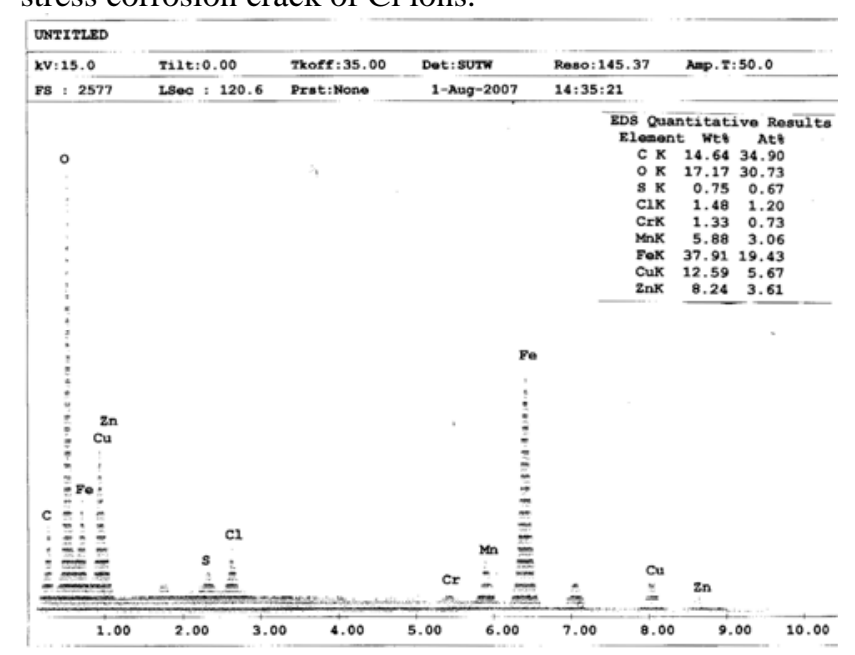

Fig.6 Energy spectrum analysis of the corrosion products of 1\# sample fracture section

\section{Conclusions and Recommendations}

Based on the above tests, the analysis conclusions are summarized as follows:

(1) According to the chemical composition analysis of the bolts, the fractured bolt material belongs to high manganese steel. Manganese content up is to $14.5 \%$, while chromium content is up to $9.18 \%$. Based on the chemical composition comparison, it cannot confirm the specific brand of the material, which can only be evaluated as austenitic high manganese steel. According to the metallographic structures of the material, there are a lot of unmelted carbides in the grain boundary, which indicates that the heat treatment temperature of the material is too low to melt the carbides. As a result, the material brittleness increases and corrosion resistance of the grain boundary decreases greatly, which increases sensitivity of stress corrosion.

(2) According to the analysis of the macroscopic and microscopic morphology of the bolts fracture section, the bolts fracture is characterized by brittle fracture with no shear layer at the bolts edge and no plastic deformation on the whole bolts. It indicates that the bolts ware in the state of low stress during the time of fracture, which is considered as brittle fracture under low stress.

(3) According to the analysis of metallographic structures and cracks propagation path of the bolt, the cracks grow along the grain boundary, which should be related to the striped unmelted carbide distributed on the grain boundary. The cracks extend to the weakest place (the grain boundary), and the cracks are characterized by bifurcation, which are the typical characteristics of the 
stress corrosion crack.

(4) The bolts position in the circulation pump shows that the external environment of the bolts has splash seawater, and there are a large number of chlorides on the fracture section by the energy spectrum analysis of corrosion products. It can be confirmed that the external environmental medium resulted in stress corrosion of the bolts is chlorine ion in seawater.

In sum, the main reason for the failure of these bolts are the incorrect use of the bolts material which cannot suitable for the seawater environment, and the failure of the bolts is due to the growth of the stress corrosion crack caused by chloride ions in seawater.

As a result, the measures could be taken according to the regulations and standards as follows:

(1) The materials of the bolts in service and the spare bolts shall be confirmed with the bolts provider whether consist with the original design material;

(2) The materials with good resistance to stress corrosion can be selected, such as duplex stainless steel. 022Cr23Ni5Mo3N is recommended for a specific material.

\section{References}

1. Sun B.Z., Fu D.Z.. (1984) Alloy steels manual (Volume one) . Metallurgical Industry Press, Beijing.

2. Cui Y.X., Wang C.L.. (1998) Metallic fracture analysis. Harbin Institute of Technology Press, Harbin.

3. Chen J.H., .Cao R.. (2018) Micromechanism of cleavage fracture of metals. Beijing Science Press, Beijing.

4. Ren S.Z., Zhang J.J. et al. (2003) Metallographic diagram of iron and steel. Shanghai Science and Technology Press, Shanghai

5. Wu L.S.. (1985) Failure analysis technology. Sichuan Science and Technology Press, Chengdu.

6. Chu W.Y.. (2000) Fracture and environmental fracture. Science Press, Beijing. 